(February 1900), I showed that these corpuscles existed in the neighbourhood of a hot wire and of a metal plate illuminated by ultra-violet light, and recently the discovery by Giesel, Curie and Becquerel of the magnetic deflection and electric charge carried by part of the radium radiation may be interpreted as indicating the existence of corpuscles in this substance.

I suppose, then, that there is a certain amount of what may be called corpuscular dissociation taking place in bodies ; that some of the molecules of the substance are continually breaking up by the detachment of a corpuscle, and are being reformed by the arrival of another corpuscle ; the result of this is that at each instant there are a certain number of free corpuscles with negative charges distributed throughout the body, while the corresponding positive charges are on the molecules of the body, the corpuscles are much more mobile than the molecules; indeed, in solids and liquids, the latter may be regarded as almost fixed in comparison with the former. We thus get the conception of a body permeated with corpuscles which are able under forces to move from one part of the body to another. We must remember that, as the particles are charged, any movement will be accompanied by electrical effects and, in general, a volume density of electrification.

The actual number of corpuscles free at any instant is the result of an equilibrium between the number of corpuscles produced by dissociation and the number which recombine. Thus if $q$ is the number of corpuscles produced by dissociation in unit volume in one second, $\tau$ the time during which a corpuscle is free (i.e. the time which elapses between its departure from one molecule and its entry into another), $n$ the number of free corpuscles in unit volumes, then when there is equilibrium $q=n / \tau$ or $n=\tau q=\lambda q / u$, if $\lambda$ is the mean free path of the corpuscle and $u$ its velocity of translation. In non-conductors we suppose that there are very few corpuscles, but that they are abundant in metallic conductors. Let us now trace some of the consequences of the existence of these corpuscles in a solid, and suppose for the moment that the positively charged molecules are fixed ; if the corpuscles are acted upon by gravity (of which point we have no evidence), then in a vertical bar of metal the number of corpuscles in unit volume will be greater at the bottom of the bar than at the top, for just the same reason as the density of the air gets less as we go higher; thus in this case gravity would produce a displacement of electricity, the bottom of the bar being negatively and the top positively electrified. Again, in a rotating mass of metal the centrifugal force would tend to drive the corpuscles towards the surface; there would thus from this effect be an excess of the corpuscles near the surface and a deficit near the axis. Thus the outer parts of the metal would be negatively and the inner parts positively electrified, the rotation of the negatively electrified corpuscles being no longer completely balanced by that of the positively electrified molecules would give rise to a magnetic field; thus a large mass of rotating metal would act as a magnet. Again, suppose we place a piece of metal in a magnetic field, the action of the magnet on the moving corpuscles will make them describe curved paths, and we can easily see that the magnetic effect due to the particles moving in this way is in the opposite direction to that of the external magnetic field. Thus a metal containing these corpuscles would tend to act like a diamagnetic substance. Again, suppose the metal is exposed to an electric force $X$, the corpuscles will acquire an average velocity along $x$ equal to $\mathrm{X} \tau e / 2 m$, where $m$ is the mass of a corpuscle and $e$ its charge. Let us call this velocity $v \mathrm{X}$, then the electric current across unit area is nev X t thus nev or $q e^{2} \lambda^{2} / 2 m u^{2}$ is the specific conductıvity of the substance. If we suppose that $u$, the mean velocity of translation of the corpuscles, varies with the temperature in the same way as the velocity of translation of the molecules of a gas, $m u^{2}$ would be pro- portional to the absolute temperature, and the specific resistance would, considered as a function of the absolute temperature $\theta$, vary as $\theta / q$; if $q$, the amount of ionisation increases as the temperature increases, the resistance will vary more slowly than the absolute temperature ; if $q$ diminishes as the temperature increases, the resistance would vary more rapidly than the temperature. These corpuscles moving from place to place would carry not merely electric charges, but energy from one part to another ; and since the coefficient of diffusion of these corpuscles is proportional to $v$, the thermal and electric conductivities would be proportional to each other. Again, when we have conduction of heat we have unequal streams of these corpuscles in opposite directions; thus the unequal deflection of their paths produced by a magnet would give rise to an electric displacement, and we should have an electromotive force at right angles to the mag. netic force and to the temperature gradient, an effect discovered by v. Ettinghausen and Nernst. From the conductivity of the gas we can deduce the value of nev. We know the value of $e$, and hence another equation would enable us to determine $n$ and $v$; for this purpose we turn to the Hall effect, but here the results are disappointing, for we can easily prove that when $\mathrm{E}^{1}$ and $\mathrm{E}$ are the tranversal and longitudinal electric forces and $\mathrm{H}$ the magnetic force, $\mathrm{E}^{1} / \mathrm{EH}=\frac{v_{1} k_{2}-v_{2} k_{1}}{k_{1}+k_{1}}$, where $v_{1}$ and $v_{2}$ are respectively the velocities of the negative corpuscles and positive molecules under unit electric force, and $k_{1}$ and $k_{2}$ the values of $k$ for these ions where $k=$ pressure $\div$ number of systems in unit volume. If both the negative corpuscles and the positive molecules behave like perfect gases, $k_{1}=k_{2}$ and $\mathrm{E}^{1} / \mathrm{EH}=\frac{1}{2} z_{1}$, since $v_{2}$ is very small ; thus, on this supposition, the Hall effect would give us the value of $v$; but there seems no reason to suppose that the positively electritied molecules in the solid would produce the same pressure as an equal number of molecules in the gaseous state, and thus though $v_{2}$ is small compared with $v_{1}, k_{2}$ may be so small compared with $k_{1}$ that $k_{1} v_{2}$ cannot be neglected in comparison with $k_{2} v_{1}$, and in this case the Hall effect would not be sufficient to determine $v$. The fact that the Hall effect is of different signs for different substances shows that we have to take into account both terms in the expression for $\mathrm{E}^{1} / \mathrm{EH}$.

Again, if different parts of a metal bar were at different temperatures, the "pressure" as it were of these corpuscles would be different at different parts of the bar, so that the corpuscles would tend to flow from one part of the bar to the other, and cause an electric displacement; thus difference of temperature would cause an electric displacement. This is the Thomson effect, measured by the "specific heat of electricity." The value of the "specific heat of electricity" will on this theory depend not only on the variation with temperature of the kinetic energy of a single corpuscle, but also on the way the dissociation constant $q$ varies with the temperature. There are many other phenomena which can be interpreted in terms of these corpuscles, but these I must leave for another occasion.

Cavendish Laboratory, Cambridge, April 30.

\section{SCIENCE IN RELATION TO ART AND INDUSTRY.}

$\mathrm{A}^{\mathrm{T}}$ the annual banquet of the Royal Academy on Saturday evening, Sir Norman Lockyer, in replying on behalf of science, made the following remarks upon the intimate relation between intellectual progress and the study of nature, and also upon the necessity for a more liberal provision for scientific work if England wishes to compete successfully with other nations struggling for industrial supremacy. Though the public mind may be

No. [ 593. VOL. 62] 
disturbed by the statement of the principle that the provision made for scientific and technical study and research should be as great as that given by any two other nations, the comparison will serve a useful purpose in directing attention to a view of the claims of science worthy of consideration.

It is a very great honour for a student of science to be called upon in such an august assembly as this to say a few words; but if $I$ am to be accepted as the representative of science $I$ do not wish to be fettered by your suggestion, Sir, that I should refer to the dependence of art on science. I am sure that I may frankly say for every man of science that we acknowledge freely the firm brotherhood between art and science-a brotherhood founded upon a common object, the study of Nature, "the mistress of all the masters," and carried on by a common method, the proper co-ordination of brain, hand and eye. In every case with which a man of science or a man of art has to deal, imagination is required, and so science and art meet upon terms of mutual helpfulness. I think I may also say that this feeling is thoroughly reciprocated by men of art, for many of them honour me with their friendship, and therefore I know their sentiments. I am the more anxious to say this because some twenty years ago, when I was privileged to attend this anniversary dinner, I heard a distinguished representative of literature express a totally different sentiment. He told us that "before their sister, Science, now so full of promise and pride, was born, there were Art and Literature like twins together," and it was suggested that the sooner art and literature formed an alliance offensive and defensive against the interloper, the better it would be for them. I do not believe in this. For me science is as old as art. They have both advanced together. Let us take the position of things 6000 years ago, to begin at the beginning of things, if we can. Then the priest-mummifiers of Menphis had to be profound anatomists. If you go to the Gizeh Museum you find magnificent specimens in those statues of Chepren in diorite, other statues in wood, and the plaques, veritable Memlings in stone, which clearly show that this knowledge was also possessed by their sculptors. If you come down to a comparatively modern period, something like 600 B.C., and compare those wonderful metopes of Solinunto with the marbles of the Parthenon, which are of a later date, you will find an enormous advance in the latter. You will find that Hippocrates had lived in the interval, and, indeed, that he and Phidias were contemporaries and fellowtownsmen. Carrying the matter down to the introduction of Universities into Northern Italy in the thirteenth century, we find that the difference between the art of Cimabue and Giotto depends on the fact that anatomy had been introduced in the meantime. Science, then, is no new interloper, seeking to detract from the importance of art and literature. What was new twenty years ago was that the work of the late Prince Consort, whose name will always be revered by those who know the benefits he conferred on our country, was then beginning to tell. He showed us that in order to secure industrial progress we must have, above all things, instruction and practice in science and art. In war, being well assured of the valour and endurance of our sailors and soldiers, the chief thing we have to do is to see that they are properly supplied with the engines and munitions of war, and, more than these, the scientific spirit. In peace, for the beauty of a nation's life and a perfect record of it, we must look chiefly to the sweetening and ennobling influences of art and the enduring works of its masters; but for a nation's continued welfare and progress both science and art are necessary. We are in face of industrial struggles, and we must utilise both science and art to supply the wants of our own and other countries, and to provide commodities made in England, besides handling

$$
\begin{aligned}
& \text { "Things of beauty, things of use, } \\
& \text { That one fair planet can produce, } \\
& \text { Brought from under every star." }
\end{aligned}
$$

We are in face of a struggle for existence in which we know full well that only the fittest will survive. How are we going to carry on the struggle? What are our weapons? Our first line of defence in this direction can only consist of our Universities and our teaching centres. Have we enough of them? We know already that we have not enough of them, because we have already lost several important engagements in these industrial battles. Are there no means by which we can judge of their sufficiency? In relation to non-peaceful international struggles in which also defeat has to be guarded against, a clear and

$$
\text { No } 1593 \text { voL. 62] }
$$

universally approved policy has been enunciated; this is, that the future of our empire, an empire the real unity and strength of which are developing under our eyes at this moment, can be secured if we see to it that our first line of defence, our fleet, shall be equal in strength to the fleets of two other possibly contending powers. The second answer then, I think, is that this principle should be applied to our first line of defence in those industrial conflicts the results of which are much more enduring. Do our teaching and research centres at present outnumber in the same proportion, as do our ships, those of any two nations which are actually contending with us in peaceful enterprise? And, also, are they equally efficient in every respect? I believe, and I know that this view is held by many representative men of science, that until our Universities, our science schools, our art schools, and our technical institutions bear the same relation both in number and efficiency to those of other nations as do our battleships, cruisers, and small craft, we shall not be justified in regarding the future of the empire with that freedom from care which is the attribute of a strong man armed.

\section{NOTES}

Prof. E. Suess, professor of geology in the University of Vienna, has been elected a Foreign Associate of the Paris Academy of Sciences, in succession to the late Sir Edward Frankland. Sir John Burdon-Sanderson, Bart., has been elected a Correspondant of the Academy, in succession to the late Sir James Paget.

Dr. S. L. Törnquist, of Lund (Sweden), has been elected a Foreign Member of the Geological Society, and Prof. F. Sacco, of Turin, has been elected a Foreign Correspondent.

WE much regret to see the announcement of the death of Lieut.-General Pitt-Rivers, F.R.S., the distinguished anthropologist, on Friday last.

THE annual conversazione of the Society of Arts will be held at the Natural History Museum, South Kensington, on Wednesday evening, June 20.

THE adjourned debate on the Sea Fisheries Bill was resumed in the House of Commons on Monday. After a long discussion, a division was taken, and a majority was obtained in favour of the second reading. The Bill was then referred to a Select Committee.

IT is reported that Vesuvius has shown signs of increased activity during the past few days. Explosions have taken place in the crater of the volcano, and masses of rock and lava have been ejected. The huts of the guides and the topmost station of the funicular rail way are threatened. Reuter reported that four Englishmen who ascended Vesuvius on Tuesday went beyond the limit indicated as dangerous by the guides and gendarmes, and were seriously injured by a mass of ejected material striking them. This however has since been denied by Reuter's Naples Correspondent.

THE U.S. National Academy of Sciences has decided to award the Barnard medal to Prof. Röntgen for his discovery of the X-rays. This medal is awarded at the close of every quinquennial period for a discovery in physical or astronomical science, or novel application of science to purposes beneficial to the human race. The first presentation of the medal was to Lord Rayleigh and Prof. Ramsay for their joint discovery of argon.

Reuter's Agency learns that Dr. Louis Sambon and Dr. G. C. Low, who has been awarded the Craggs research scholarship of $300 l$. per annum, are about to experiment with a view to proving that malaria is spread by mosquito bites, and expect to begin work seriously on June $\mathrm{I}$, by which time they will have all their arrangements completed. A suitable spot has been chosen 